suspected and on Jan. 5, 1909, a paracentesis of the pericardium was performed under local anesthesia (ethyl (hlorid) but no fluid was obtained. The patient's condition rapidly grew worse, all symptoms increasing in sererity and the dyspnea became intense (respirations, 60). The leucocyte count reached 89,000 . The septic condition was then believed to be due oniy to a pyogenic infection of the aortic valves. ) bath occurred on the evening of Jamury 7 .

Autopsy.-This revealed a large mass of fleshy, vegetative excrescences on the aortic valres, about the size of the end of the thumb. When these were removed for the purpose of making sections, a considerable amount of thick, yellow pus exuded from beneath the leaflets. Both pleural cavities were almost entirely obliterated by dense adhesions, undoubtedly the result of a pleuritis following the previous attack of "typhoid-pneumonia." The liver and spleen were both enlarged and congested, the latter organ showing evidences of amyloid degeneration. Cultures were made from the pus obtained from the aortic lesion and from the chancroid, and the same organism (Staphylococcus pyogenes aureus) was isolated in pure culture from both localities. Stained sections of the diseased valves showed numerous purulent foci.

'The fact that the chancroid was the only perceptible abrasion on the body surface, the isolation of the same o:ganism in pure culture from both places, and the sudden onset of the septic condition following the chancroidal infection, all seem to indicate that the malignant endocarditis was the sequel of the venereal infection.

U. S. Naval Hospital.

\section{INTESTINAL RESECTION WITH END-TO-END ANASTOMOSIS BY PARKER-KERR METHOD: RECOVERY}

\section{SCOTT D. BRECKINRIDGE, M.D.} WASHINGTON, D. C.

Patient.-A colored man, aged 31 , was brought into Providence Hospital by Dr. Scott, of Anacostia, Dec. 5, 1908, for immediate operation for a strangulated left inguinal hernia, the strangulation being of about twelve hours' duration.

Operation.-The hernia was exposed and the sac incised in the usual manner, the contents consisting of twelve inches of gangrenous small intestine and a small portion of the omentum which was adherent to the bottom of the sac. The intestine failing to react to the application of hot saline solution, the narrow clamps adopted by Parker and Kerr ${ }^{1}$ in their work were applied transversely to the axis of the intestine, one inch outside of the gangrenous portion, and resection performed. A Cushing continuous right-angled suture (the "basting-stitch" of Parker and Kerr) was then applied over the clamps; the clamps were withdrawn, and the "basting-stitches" drawn taut, perfect invagination resulting. End-to-end anastomosis was then performed by means of a silk continuous Lembert suture, reinforced by two or three interrupted Lembert stitches of the same material. The "basting-stitches" were then cut short and withdrawn without the slightest difficulty. The line of anastomosis was rolled between the thumb and finger to open the lumen and a portion of the intestinal wall invaginated through the anastomosis to test its patency. The intestine was then returned to the abdominal cavity and the wound closed.

l'ostoperatice History.-The patient romited once after the anesthetic and at no time suffered from distention or from any disturbing symptom. His temperature and pulse reached normal on the third day and he made an uneventful recovery, being discharged well a little over three weeks after the oper ation.

I place particular emphasis on the perfect invaginating action of the "basting-stitches" and the perfect ease

1. Parker, Fdward Mason, and Kerr, Harry Iyland: Intestinal Anastomosis without Open Incision, by Means of Basting-Stitches, Johns Hopkins. Iosp. Jull., May, 1908 with which they were withdrawn after the completion of the anastomosis. This "closed "method is undoultelly cleaner and, in my opinion, simpler than the ordinary methods by use of clamp and suture, or Murphy bution.

\section{A PERMANENT APPENDICULAR VESICO- CECAL FISTUIAA}

\section{R. CADWALLADER, M.D. \\ SAN FRANCISCO}

The following case report shows one result of appendicitis:

History.-A girl, aged 20, was bronght to me with the following history: She was the ehild of healthy parents, a nor. mal baby with a normal history. She liad had the usual diseases of childhood. When she was about eight I treated her for peristent bed-wetting. The usual remedies gave little benefit, and, while my records are now lost, I remember tolling her mother that $I$ thought it wonld end at puberty. There was no congenital malformation of any kind. Menstruation began when she was eleven in a perfectly normal manner and, as expected, the enuresis ceased. Soon after this, when about 12 year's old, she noticed that a consiclerable quantity of mucus and pus was passing in the urine at times, with soreness of the bladder. This was more marked when the bowels were loose. With this there was for years a history of colicky pain in the abdomen, but at no time did it confine her to bed or simulate an acute attack of appendicitis. thout three years ago this extraneous matter was found to be fecal in nature and is thought by her to luave been occasionally passed for the greater part of her life. It was never constant and was usually the seeds of fruit, husks of grain, mucous and brown colored debris. It was not always of fecal odor. At times there was the passage of gas with the urine, of decidedly fecal odor and considerable noise, and she feels sure that several times there was urination from the bowel. With this history she was sent to me for operation.

Dicignosis.-I will pass quickly over the many tests by which I tried to establish all this as true. Inflation of the intestine and bladder were without success. Iron by mouth could not lee found in the urine nor did methylene blue escape by the rectum. For days nothing would appear and then the catheter would bring blackberry seeds, pear] barley, or striped muscle fibers in accord with her diet. I used the Kelly cystoscope and made out the ureteral openings and most of the bladder wall to be normal and uninflamed. Dr. John C. Spencer was called in and we used the Nitze instrument and satisfied ourselves that there was nothing abnormal in base or walls except a spot on the fundus that might be an opening. Here was a dark patcl or crater at one spot of the border of which was some inflammatory tissue. It was not conclusive but I decided to clear up the mystery by a laparotomy and even open the bladder if nothing was found in the abdomen to account for the symptoms.

Operation.-On January 3, with the assistance of Dr. Campbell Ford, I opened the abdomen and found first a large adhesion of the ileum to the fundus which was carefully separated but which did not communicate with the bladder. Under this we found the tip of the appendix adberent to the bladder at about the peritoneal reflexion over the uterus in the merlian line. The tip was embedded in the wall and seemed to form a part of it. It was about $7 \mathrm{~cm}$. long and uniform ii diameter. The succeeding steps were simple. A cuff of peritoneum and muscle was turned from either end and the median part eut away; the stumps were disinfected, the cuffs were ligated over the stumps and the abdomen was closed with the Ford stitch. Recovery was absolutely without interest and the patient left the bed a week later.

Were it not for the adhesion found I should be inclined to consider the condition congenital, but in the only other case like this, that of Keen's, I find that he 